\title{
Improving operating room start times in a community teaching hospital
}

\author{
Alex Darwish, Pratik Mehta, Ahmed Mahmoud, Amr El-Sergany, David Culberson \\ San Joaquin General Hospital, United States
}

Received: November 17, 2015

Accepted: February 21, 2016

Online Published: March 1, 2016

DOI: $10.5430 /$ jha.v5n3p33

URL: http://dx.doi.org/10.5430/jha.v5n3p33

\begin{abstract}
Introduction: The operating room (OR) is an expensive entity to manage. Efficiency in hospital resource utilization is critical for hospital financial solvency. One measure of efficiency in the OR is percentage of on-time starts for cases at the beginning of each day. This study looks at a community teaching hospital where measures were taken to identify and address causes of tardiness in the OR.

Methods: An interdisciplinary team of doctors, nurses, and other hospital staff came together to implement a three-phase agenda. In Phase I, staff identified causes of tardiness. In Phase II, potential solutions to address each specific task were drawn up. Phase III involved maintenance of efficiency measures created in Phase II and documentation of progress for future analysis.

Results and Discussion: Over twelve months, the percentage of cases that started on time steadily increased from 14\% to $68 \%$. Additionally, of the cases that were late, the average number of minutes late decreased significantly. Of the identified causes of tardiness, surgeon arriving late was found to be the most prevalent. We analyzed the relationship between average minutes late each month and the cost and revenue per unit of service (UOS). Average minutes late per month and hospital revenue per UOS showed a strong inverse correlation of -0.83 , while average minutes late per month and cost er UOS showed a moderate positive correlation of 0.62 . We analyzed the relationship between average minutes late each month and the cost and revenue per UOS. Average minutes late per month and hospital revenue per UOS showed a strong inverse correlation of -0.83 , while average minutes late per month and cost per UOS showed a moderate positive correlation of 0.62 .

Conclusions: Identifying causes of tardiness based on input from a multidisciplinary healthcare team and addressing each cause with a specific measure to combat it was effective in improving the percentage of on-time starts in the OR. We demonstrated that reducing delays in OR start times can both decrease cost and increase revenue. Documenting progress of efficiency measures is critical in distinguishing measures that work from those that do not. Furthermore, continued analysis of efficiency is required to maintain efficiency standards.
\end{abstract}

Key Words: Operating room, On-time starts, Tardiness, Efficiency

\section{INTRODUCTION}

Efficient management of an operating room (OR) requires thoughtful coordination of many moving parts. Costs in the OR derive from the number of healthcare providers needed to safely care for the patient and from the use of expensive equipment. Late starts at the beginning of the day can result in late finishes to cases and thereby cause over-expenditure of time and resources in the OR. In addition to the financial toll, delay in OR start time is also a source of frustration for personnel and patients. ${ }^{[1]}$ Ensuring efficiency is therefore of

\footnotetext{
*Correspondence: Alex Darwish; Email: alex.darwish.2009@gmail.com; Address:San Joaquin General Hospital, Surgery Residency Program, 500 W Hospital Road, French Camp, CA 95231, United States.
} 
critical importance in any hospital.

One metric of productivity in the OR is the percentage of on-time starts that take place per given time period. This metric can be juxtaposed on others such as cost/revenue per unit time or number of cases performed in a given time period to assess correlation, and thereafter impact on overall OR efficiency. This study elected to begin the process by addressing delays in starting the first case of the day. To achieve this, innovative time-saving measures had to be employed, which is particularly complicated in an organization where the change effort must overcome the resistance of professionals. In healthcare, physicians and staff often have deeply entrenched values and objectives that may differ from those of management. ${ }^{[2]}$ In this analysis, the objective was to align managerial and professional goals in order to improve the number of on-time starts in an OR of a county hospital in Northern California.

\section{Methods}

\subsection{Scope of study}

This study was conducted in a 200-bed community teaching hospital with 7 ORs. The hospital is also a trauma center with 1 OR dedicated for trauma 24/7. The hospital sponsors an independent general surgery residency program and only general surgery residents and attending physicians operate in the OR. The majority of operating surgeons are full time employees but the hospital is open to private practice surgeons as well.

\subsection{Need for study}

Prior to January 2014, new hospital administration became aware of frequent delayed starts, which they attributed to lack of consensus on causes of delay. A multidisciplinary team was assembled to address the subject in attempt to analyze factors leading to late OR start times and improve them. The team included hospital administrators, surgeons, OR nurses, perioperative nurses, anesthesiologists, surgery residents, and central supply personnel. The team was led by the hospital's Chief Medical Officer. The working plan of the team was divided into three phases.

\subsection{Three phase plan}

In Phase I, every member of the team was asked to state his or her view on the actual causes of the delay in starting the first case in the OR. During this phase, all participants were encouraged to freely discuss any potential causes of delays. The pitfall of this phase was that some of the causes identified appeared like accusations of other team members. For example, surgeons were blamed for poor/outdated documentation and delay in marking operative site. Nurses were criticized for taking too long to do their pre-operative checklist and transporting the patient into the room. Anesthesia providers were often accused of ordering last minute blood tests on some patients (e.g. full electrolyte panels on dialysis patients). It was imperative that all participants felt comfortable addressing issues and that a collegial atmosphere was maintained. No restriction was given on any cause given by any team member. Regardless of its merits, every cause stated by any team member was documented in Phase I meetings. All causes mentioned were later analyzed for factuality by reviewing patient records from the previous year. After a comprehensive review of all examples mentioned, the 10 most frequent causes were moved to Phase II and addressed by the team members. Table 1 lists the 10 most frequent causes of delay.

Table 1. Identified causes of tardiness

\begin{tabular}{cl}
\hline Number & Cause \\
\hline 1 & Surgeon late \\
2 & Anesthesia needed more time \\
3 & Anesthesia late \\
4 & Further workup needed \\
5 & Poor Documentation \\
6 & Bumped by emergency \\
7 & Nursing delay \\
8 & Equipment readiness \\
9 & Patient late \\
10 & Pharmacy delay \\
\hline
\end{tabular}

During Phase II, the 10 causes of delay originating from Phase I were presented to the team members as a group. Group members were asked to provide potential solutions to each cause specifically. Team members were asked not to use any "blame team" tactics in their suggested solutions. To a large degree, avoiding blame was one of the major challenges in this project.

Suggested solutions for causes of delay were then studied by the group as a whole. These suggestions came from previous experience of staff members or reasonable justification to implement the solution according to previous knowledge of standard practices. Tasks were extracted from each solution and then designated to separate members of the team for implementation. We screened for obstacles of the tasks before attempting to implement them in order to avoid the potential pitfall of impracticality (see Table 2).

Phase II ended after devising of a comprehensive plan to implement all of the tasks, which had been designated to different members of the team. Monitoring of implementation and feedback to the group was a continuous process to maintain the plan dynamic and avoid theoretical impotence. Modifications of tasks were created as feedback continued. 
Table 2. Identified causes of tardiness and corresponding proposed solutions

\begin{tabular}{|c|c|c|}
\hline Number & Cause & Solution \\
\hline 1 & Surgeon late & $\begin{array}{l}\text { - Remediation and penalties for repeat offenders ranging from shortened block time to } \\
\text { complete loss of block time }\end{array}$ \\
\hline 2 & Anesthesia needed more time & $\begin{array}{l}\text { - Increasing staffing to allow for cross-coverage* } \\
\text { - Improving efficiency of pre-operative checklist }\end{array}$ \\
\hline 3 & Anesthesia late & $\begin{array}{l}\text { - Remediation and penalties for repeat offenders e.g. limited selection and priority in } \\
\text { selecting cases }\end{array}$ \\
\hline 4 & Further workup needed & $\begin{array}{l}\text { - Having all cases approved by attending physicians before scheduling; review of } \\
\text { pre-operative labs and imaging a few days before surgery }\end{array}$ \\
\hline 5 & Poor Documentation & - Confirming dictated up to date History \& Physical in chart during pre-operative visit \\
\hline 6 & Bumped by emergency & $\begin{array}{l}\text { - Creating a separate trauma room }{ }^{*} \\
\text { - Additional staff }\end{array}$ \\
\hline 7 & Nursing delay & $\begin{array}{l}\text { - Additional flexible part-time staff according to work needs } \\
\text { - Improvement in nursing training for efficiency checkups }\end{array}$ \\
\hline 8 & Equipment readiness & $\begin{array}{l}\text { - Increased efficiency and training of central supply personnel } \\
\text { - Objective feedback from surgeon to central supply personnel }\end{array}$ \\
\hline 9 & Patient late & $\begin{array}{l}\text { - Pre-operative counseling by phone } \\
\text { - Call on day of surgery to confirm time of arrival }\end{array}$ \\
\hline 10 & Pharmacy delay & - Pre-operative antibiotics ordered during scheduling \\
\hline
\end{tabular}

${ }^{*}$ These measures are accounted for in cost/revenue data per unit of service (see Figure 4)

Table 3. Percentage of first cases of the day that start on-time versus late between January $1^{\text {st }}$ and December $31^{\text {st }} 2014$

\begin{tabular}{lllll}
\hline Month & $\begin{array}{l}\text { Percent of first cases } \\
\text { on time }\end{array}$ & Percent of first cases late & $\begin{array}{l}\text { Average minutes late } \\
\text { of first case }\end{array}$ & $\begin{array}{l}\text { Total minutes late on } \\
\text { first cases }\end{array}$ \\
\hline January & 14 & 86 & 29 & 3,168 \\
February & 16 & 84 & 30 & 3,162 \\
March & 20 & 80 & 26 & 3,011 \\
April & 52 & 48 & 11 & 1,645 \\
May & 56 & 44 & 11 & 1,158 \\
June & 53 & 47 & 11 & 1,160 \\
July & 61 & 39 & 13 & 1,403 \\
August & 74 & 26 & 5 & 492 \\
September & 71 & 29 & 13 & 1,774 \\
October & 66 & 34 & 7 & 749 \\
November & 70 & 30 & 6 & 481 \\
December & 68 & 32 & 7 & 762 \\
\hline
\end{tabular}

Note. Shown in the table are the calculated average and total minutes late on the first case(s) of the day each month. This gives an idea of the effectiveness of efficiency measures aimed at preventing tardiness in the OR

Phase III involved maintenance of efforts and measuring the impact of changes. The process of feedback continued during all phases and consisted of each member of the team carrying out a solution to an identified problem and then reporting back to the multidisciplinary team.

\section{Results}

\subsection{Overall efficiency}

Our study used "wheels in" as the definition of the start of all cases in the OR and a grace period of 5 minutes was allowed for a case to begin behind schedule. Over twelve months, the percentage of on-time OR starts improved from $14 \%$ to $68 \%$. Furthermore, the average number of minutes delayed and

Published by Sciedu Press total minutes late on all first cases in each month dropped significantly. This is demonstrated clearly (see Tables 3, Figures 1 and 2).

\subsection{Causes of tardiness}

The causes of tardiness identified by the team members were essential metrics taken during the period of study. The leading cause of first case delay was tardiness of the surgeon, followed by need for further workup, Anesthesia Department needing more time, a case being bumped, and delay in nursing. A full list of causes for delay in June of 2014 is shown in Figure 3 and serves as a representative for a typical month during the course of study. 


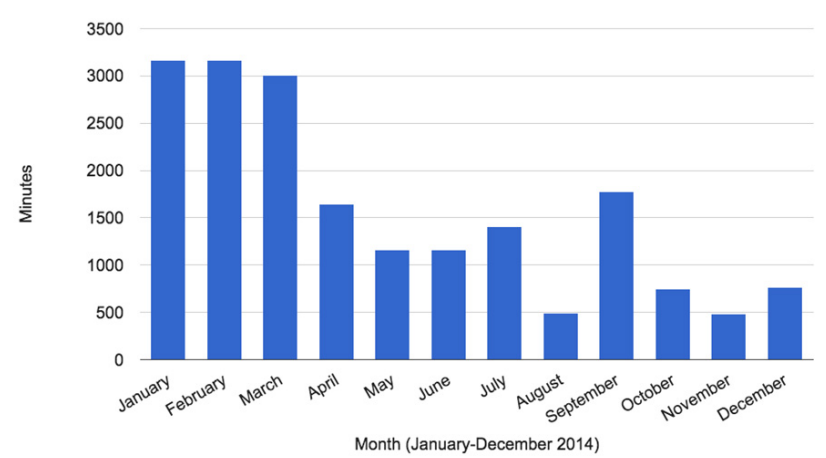

Figure 1. Total number of minutes late on the first case(s) of the month

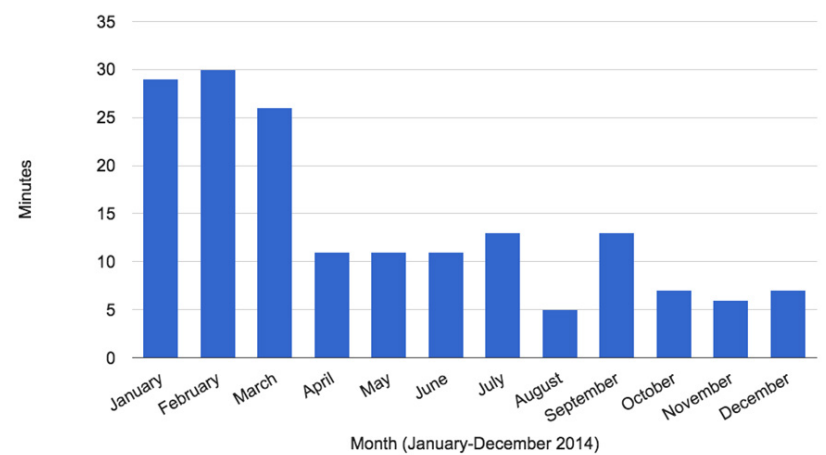

Figure 2. Average number of minutes late on the first case(s) of the month
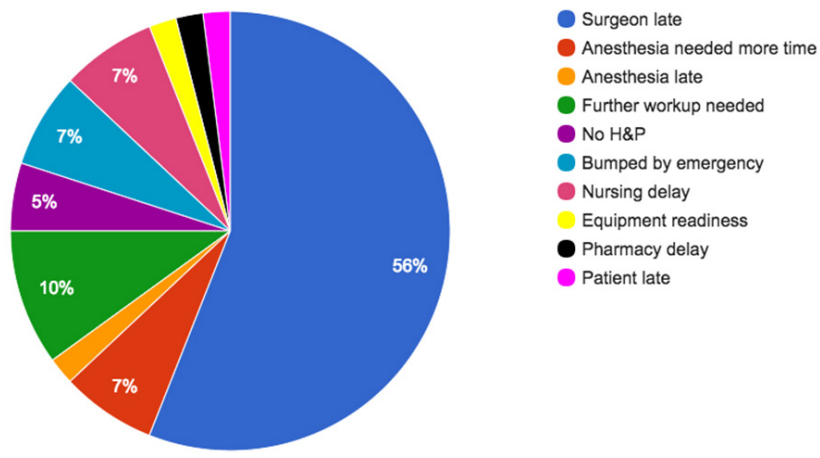

Figure 3. Causes of tardiness in the OR in June 2014. As shown here, the leading cause of tardiness was the surgeon being late

One important point regarding the lead cause of delayed OR start times in this study, tardiness of the surgeon, is that the surgeon being late can often be a secondary result of a separate cause of delay, such as need for further workup or anaesthesia needing more time. ${ }^{[3]}$ If this is the case, it is economically rational for the surgeon to arrive late. In this study, however, those documenting causes of tardiness made sure to only document the primary cause of tardiness rather than the ultimate and often more easily identifiable result of surgeon tardiness. To do this, multiple team members confirmed the cause of delay in a cooperative and non-accusatory fashion. Reasons for primary surgeon tardiness separate from the causes of delay included in Figure 1 include: need to finish morning rounds, need to review a patient's lab/imaging results, and need to consult with radiology.

\subsection{Effect of tardiness on cost and revenue per unit of service (UOS)}

To determine the financial impact of tardiness in the OR, the hospital's revenue and cost incurred in order to support the OR were analyzed. If a strong correlation to improvements in start times was found, the effectiveness of time-saving measures would be validated and allow for potential further improvement and fine-tuning. Note that a UOS represents one minute of operating time in the OR.

As demonstrated in Figure 4, average minutes late show the most obvious unidirectional change, trending downwards over the twelve months as a direct result of efficiency measures established in Phase II of the initiative. It is probably logical to suggest that time-saving measures should incur less cost on the hospital, since they relieve the hospital from the responsibility of supporting excess cost of equipment use and non-salaried employee pay. The cost curve (red) shows a slight downward trend parallel to average minutes late (blue). To quantitatively determine the significance of the relationship between these two variables, we calculated the Pearson's correlation to be $0.62(\mathrm{n}=9, p=.075)$, which represents a positive correlation that is not statistically significant. This is likely because of the incurred costs by implementing some of the time-saving measures proposed in Phase II, such as additional part-time staffing. Next, we looked at the relationship between revenue and average minutes late per month, corresponding to the blue and yellow curves in Figure 4. The Pearson's correlation between revenue and average minutes late was stronger, $-0.83(\mathrm{n}=9, p=.006)$, the negative sign indicating an inverse relationship. Note that there are three months (April, May, and June) for which cost and revenue data are not available, but the smoothed line over this period does not skew the correlation numbers.

\subsection{Effect of tardiness on number of cases able to be per- formed}

After establishing the effectiveness of time-saving measures demonstrated in the correlation numbers between lateness and cost/revenue, an attempt was made to determine if the improved efficiency measures may have allowed the OR to take on more cases. Certain cases are able to be performed non-emergently within a given period of time, and the time at 
which they are performed depends on volume of the OR and availability of surgeons. This makes it economically rational to wonder if improved OR start times on the first case of the day reduce the waiting time for these patients and allow more cases to be performed. Figure 5 charts average minutes late on the first case each month with the total number of OR procedures performed each month. As can be seen, the correlation is weak and not statistically significant $(R=-0.17$, $\mathrm{n}=12, p=.597)$.

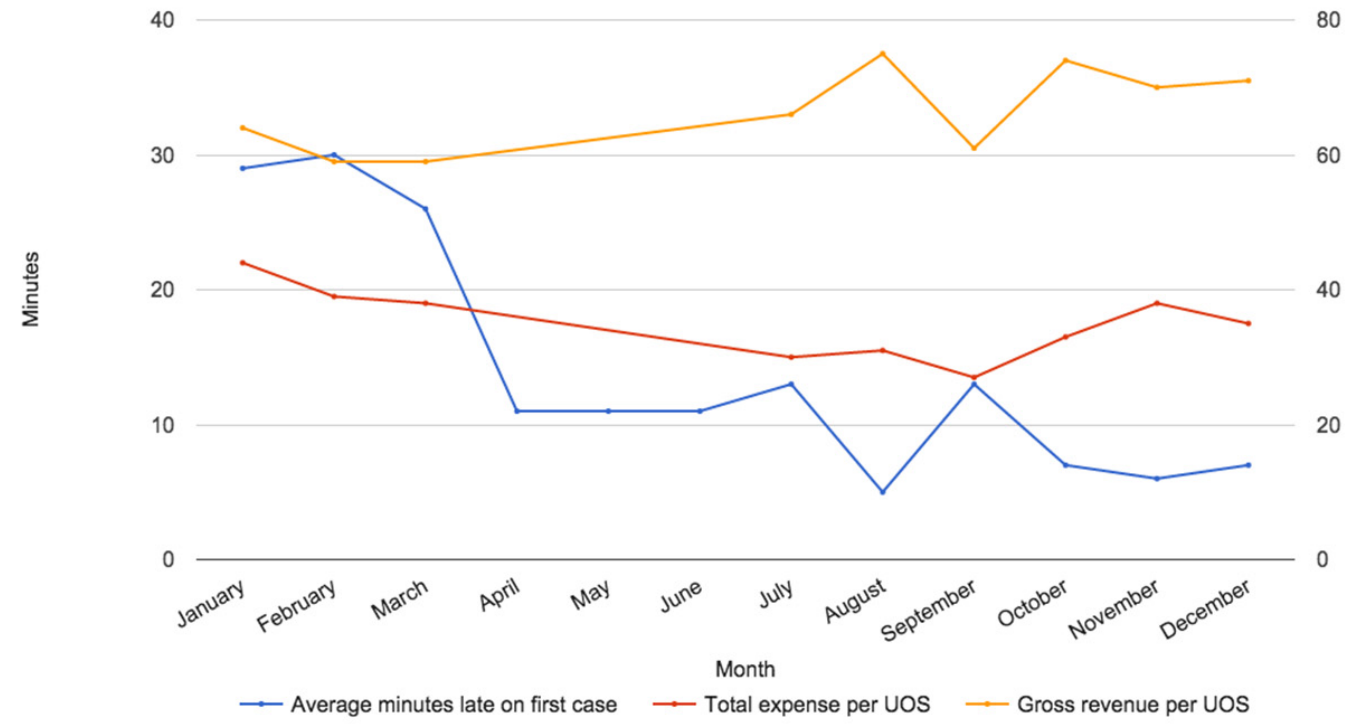

Figure 4. Relationship between average minutes late of first case and revenue/cost per UOS 1 UOS $=1$ minute of operating time in the $O R$

40

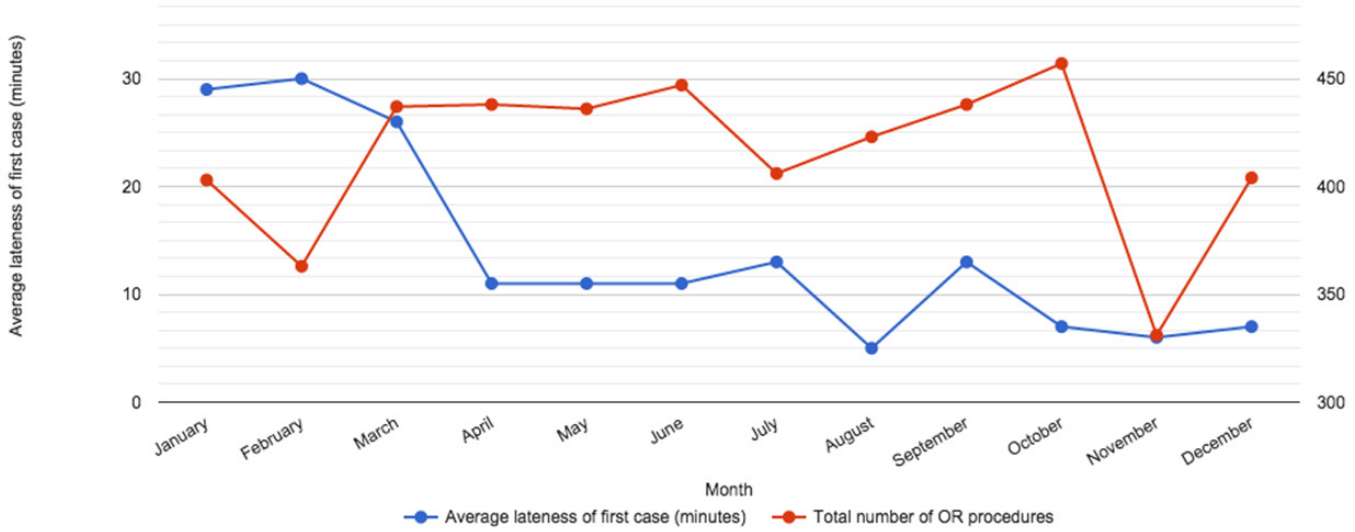

500

Figure 5. Relationship between average minutes late on first case and total number of OR procedures performed each month

\section{Discussion}

Starting on time is a critical foundation in ensuring productivity and efficiency in the OR. Review of the literature reveals that hospitals have employed various approaches to accomplish this including: punitive measures such as loss of allocated block time, motivational pleas to employees through formal presentations, and even specialized task forces dedi- cated to ensuring on-time starts. ${ }^{[4,5]}$ This study focused on identifying causes of tardiness and tackling each issue with an individualized solution to rectify it. Other variables considered included: percent of first cases of the day that started on time, cost and revenue per UOS in management of the OR each month, number of cases which could be performed per month, all relative to the number of minutes tardy in 
beginning the first case of the day.

The definition of start times varies widely in the literature. ${ }^{[4-6]}$ Some authors use "wheels in" while others use "knife on skin". In our study, starting time was determined based on when the patient arrived to the OR, or "wheels in" time. Due to hospital policy, patients were not brought to the OR until nursing, anesthesia, and the surgeon were physically present and ready to start the case. This prevented delays between "wheels in" and "knife to skin" times. Additionally, "wheels in" more precisely characterized the time an OR was being utilized. Focusing on the first case of the day allows one of the major causes of delay in the entire OR, complications in scheduled cases, to be eliminated so that preventable causes can be more directly addressed. ${ }^{[6]}$ Emergent non-scheduled cases, although not preventable, are still considered as a cause of delay (see Table 1 and Table 2).

Some authors have analyzed the efficiency of their ORs using the same measures. Overdyk employed a similar methodology to ours, using an initial phase of study to collect data on causes of delay in OR start times, followed by a multi-phase implementation initiative. ${ }^{[7]}$ An important step incorporated in their project was prominent display of ongoing data collection on timeliness to hospital employees. A different methodology was used in our study where the multidisciplinary team designed a three phase approach with initial subjective description of causes of delay and continuous verbal feedback during the improvement process. In comparison to the Overdyk study, our study encompassed more stakeholders in open-ended discussions that encouraged them to take an active role in changing the culture.

A common goal of many OR utilization papers is to determine the monetary benefit of improving OR efficiency. A study by Does et al. estimated the cost of running an OR to be approximately $\$ 1,500$ per hour and from there, extrapolated that losing 2,150 hours of productivity in a year should correspond to $\$ 3.2$ million per year in lost revenue. ${ }^{[8]}$ In our hospital, this calculation was not exercised based on differences in fixed and variable costs in our small community hospital model. Fixed costs included pay to salaried employees and cost of central supply equipment use, while the most significant variable cost was pay to per-hour and part-time staffing. The hypothesis in this study is that reduction in late OR start times should result in reduction of variable costs and thereby reduce overall costs for the OR. ${ }^{[4,5]}$ We used cumulative cost per UOS ( 1 UOS $=1$ minute) each month as an efficiency metric to account for the differences in fixed and variable costs.

Utilization is a surrogate marker for OR efficiency. ${ }^{[9]}$ The classic definition of OR utilization is the sum of the time it takes to perform each surgical procedure plus the total turnover time divided by the time available. Underutilization is defined as time during the scheduled day not used for operations and overutilization is time used after the end of the scheduled day to finish cases. ${ }^{[10,11]}$ Cardoen et al. note the distinction between overutilization/underutilization and overtime/undertime pay, since it is possible for a hospital to pay employees overtime on a day in which the hospital ORs were underutilized. For example, imagine two ORs with daily capacities of 4 hours. If one is used for 2 hours, and the other for 5 hours, the two ORs will have been used for only 7 of the available 8 hours, but overtime will be paid to some employees involved in the longer case. Because of this distinction, many authors refer to utilization as the workload of a resource while overtime/undertime includes a timing aspect. ${ }^{[12]}$ Utilization rates are dependent on many factors, such as appropriately booked cases on the schedule, consistent case durations, consistent predictions for case durations in scheduling, quick turnovers, low case cancellation rates, Postanesthesia care unit (PACU) admission delays, and timely starts on the first case. ${ }^{[4,5,13]}$ Uses of other efficiency metrics are viable indicators and could be targeted for future work by other authors in similar analyses.

Some of the limitations of this study are related to the small hospital size, the subjective rather than objective analyses of various causes of tardiness, in addition to the possibility of the Hawthorne effect. The small hospital size, although a factor, this study is specifically targeted towards hospitals of similar volume, with comparable resources and almost equivalent causes of tardiness. A potential reporting bias was the sole reporting of tardiness by nursing staff. A future study should consider an automated system to record OR start times without a need for human intervention.

Another consideration in our study was the effect of observation bias, or the Hawthorne effect, in producing improved efficiency metrics by hospital staff in the OR. The Hawthorne effect, which is the tendency of people to modify or improve their performance in a research setting compared to normal. ${ }^{[14]}$ Although the possibility of the Hawthorne effect can not be totally excluded from this study, the persistent improvement over a period of 12 months is in support of improved efficiency strategies rather than just an isolated Hawthorne effect, which typically fades away with time, as the cause of improvement. ${ }^{[15]}$

A unique aspect of our study was the small size hospital, the limited resources used to make improvements in the OR, and the collective effort placed by the interdisciplinary team towards transforming subjective causes of delay into more objective steps towards improvement. In the future, we will 
continue to use the time-saving methods we established in Phase II of the initiative so that an even higher percentage of on-time OR starts might be achieved. Most studies analyzing various metrics of productivity in the OR concur that consistency is key to achieving maximum efficiency. Over a longer period of time, we hope these measures are able to increase the productivity of the OR by making room for added cases, reducing hospital costs, increasing hospital revenue, and reducing the frustration of hospital employees and patients that results from tardiness.

With the many challenges facing healthcare industry there is a financial burden placed on small hospitals. The results of our study should be encouraging for similarly sized hospitals intending to maximize their use of limited resources. The significance of a multi-disciplinary team with many stakeholders, the design for improvement in three successive phases, and continuous feedback were elements for success in our work. Institutions with similar capacities could replicate our model for improving OR efficiency.

\section{ACKNOWLEDGeMents}

Angela Micheletti for keeping track of the data for Figures and Tables.

\section{CONFLICTS OF INTEREST Disclosure}

No conflict of interest to report.

\section{REFERENCES}

[1] Franklin D, Dexter EU, Johannes L. Influence of procedure classification on process variability and parameter uncertainty of surgical case durations. Anesthesia \& Analgesia. 2010; 110(4): 1155-1163. PMid: 20357155. http://dx.doi.org/10.1213/ANE.0b013e3 $181 \mathrm{~d} 3 \mathrm{e} 79 \mathrm{~d}$

[2] Agnoletti V, Buccioli M, Padovani E, et al. Operating room data management: Improving efficiency and safety in a surgical block. Bmc Surgery. 2013; 13(1): 7. PMid: 23496977. http://dx.doi.o $\mathrm{rg} / 10.1186 / 1471-2482-13-7$

[3] Warner CJ, Walsh DB, Horvath AJ, et al. Lean principles optimize on-time vascular surgery operating room starts and decrease resident work hours. Journal of Vascular Surgery. 2013; 58(5): 1417-1422. PMid: 23827339. http://dx.doi.org/10.1016/j.jvs. 2013. 05.007

[4] Wright JG, Ann R, Khoury AE. Improving on-time surgical starts in an operating room. Canadian Journal of Surgery Journal Canadien De Chirurgie. 2010; 53(3): 167-7. PMid: 20507788.

[5] Wachtel RE, Dexter F. Influence of the operating room schedule on tardiness from scheduled start times. Anesthesia \& Analgesia. 2009; 108(6): 1889-901. PMid: 19448219. http://dx.doi.org/10.12 13/ane. Ob013e31819f9f0c

[6] Janice W, Kathleen Joy K, Zul K, et al. Delays in the operating room: signs of an imperfect system. Canadian Journal of Surgery Journal Canadien De Chirurgie. 2010; 53(3): 189-195.

[7] Overdyk FJ, Harvey SC, Fishman RL, et al. Successful strategies for improving operating room efficiency at academic institutions. Anesthesia \& Analgesia. 1998; 86(88): 896-906. PMid: 9539621.
[8] Does RJMM, Vermaat TMB, Verver JPS, et al. Reducing start time delays in operating rooms. J Qual Technol. Journal of Quality Technology. 2009; 41(1): 95-106.

[9] Jebali A, Alouane ABH, Ladet P. Operating rooms scheduling. International Journal of Production Economics. 2006; 99(1-2): 52-62. http://dx.doi.org/10.1016/j.ijpe.2004.12.006

[10] Franklin D, Traub RD. How to Schedule Elective Surgical Cases into Specific Operating Rooms to Maximize the Efficiency of Use of Operating Room Time. Anesthesia \& Analgesia. 2002; 94(4): 933-942. http://dx.doi.org/10.1097/00000539-200204000-00030

[11] Tyler DC, Pasquariello CA, Chen CH. Determining optimum operating room utilization. Anesthesia \& Analgesia. 2003; 96(4): 1114-21, table of contents. PMid: 12651670. http://dx.doi.org/10.12 13/01. ANE. 0000050561.41552. A6

[12] Cardoen B, Demeulemeester E, Beliën J. Operating room planning and scheduling: A literature review. European Journal of Operational Research. 2010; 201(3): 921-932. http://dx.doi.org/10.1016 /j.ejor.2009.04.011

[13] Alex M. Are your hospital operating rooms "efficient"? A scoring system with eight performance indicators. Anesthesiology. 2006; 105(2): 237-240.

[14] Eckmanns T, Bessert JM, Gastmeier P, et al. Compliance With Antiseptic Hand Rub Use in Intensive Care Units: The Hawthorne Effect. Infection Control \& Hospital Epidemiology. 2006; 27(9): 931-4. PMid: 16941318. http://dx.doi.org/10.1086/507294

[15] Mccarney R, Warner J, Iliffe S, et al. The Hawthorne Effect: a randomised, controlled trial. Bmc Medical Research Methodology. 2007; 7(4): 1-8. http://dx.doi.org/10.1186/1471-2288-7-30 